\title{
Two Cases of Acute Erythroid Leukemia Presenting with Marked Macrocytic Anemia, Reticulocytosis and Hemolysis
}

\author{
Seisuke Ota ${ }^{1,2}$, Akinori Kasahara ${ }^{1}$, Shoma Mizuno ${ }^{2}$, Osamu Uchikoga ${ }^{1}$, Momoko Kuroda $^{1}$, \\ Haruka Miyoshi ${ }^{1}$, Kohei Shiomi ${ }^{1}$, Sachio Umena ${ }^{1}$, Toshio Noguchi ${ }^{1}$, \\ Nobuyasu Kishimoto $^{2}$ and Tadashi Matsumura ${ }^{1}$
}

\begin{abstract}
Case 1. The laboratory findings of a hematological analysis of a 53-year-old woman with palpitations and dyspnea revealed the following: red blood cell (RBC) count: $9.4 \times 10^{5} / \mu \mathrm{L}$ with $60.0 \%$ reticulocytes; $\mathrm{Hb}: 3.7 \mathrm{~g} /$

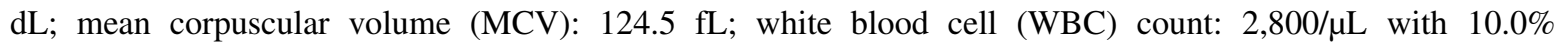
myeloblasts. Case 2. Similarly, a 42-year-old man with dizziness had a RBC count of $1.63 \times 10^{6} / \mu \mathrm{L}$ with

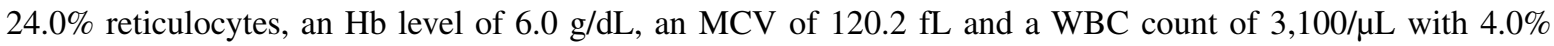
myeloblasts. Bone marrow aspirates in both patients confirmed a diagnosis of acute erythroid leukemia (AEL), which can present as marked macrocytic anemia with an MCV in excess of $120 \mathrm{fL}$ and hemolysis.
\end{abstract}

Key words: acute erythroid leukemia, macrocytic anemia, hemolysis

(Intern Med 52: 1509-1512, 2013)

(DOI: 10.2169/internalmedicine.52.0021)

\section{Introduction}

Macrocytic anemia, defined as a mean corpuscular volume $(\mathrm{MCV})>100 \mathrm{fL}$ can be caused by multiple factors, including interference with DNA synthesis due to folate or cobalamin deficiency (1-4) and liver diseases, such as alcoholinduced disorders and myelodysplastic syndrome (MDS) (5). Moreover, macrocytosis is frequently drug-related, caused in particular by hydroxyurea (inhibits ribonucleotide reductase), methotrexate (inhibits dihydrofolate reductase), zidovudine (6), azathioprine or 6-mercaptopurine, capecitabine (7) or cladribine.

Peripheral reticulocytosis is another cause of macrocytic anemia. During normal erythropoiesis, erythroid precursors (orthochromatic normoblasts) extrude their nuclei while still in the bone marrow (BM), and the MCV of the resulting reticulocytes is $120-150 \mathrm{fL}$. Reticulocytes remain in the BM for approximately three days and continue to be macrocytic following their release into the peripheral blood, where they undergo remodeling with loss of their cytosol, organelles and cell membrane. The normal MCV of peripheral reticulocytes is $103-126 \mathrm{fL}$, the mean corpuscular $\mathrm{Hb}$ concentration (MCHC) is $23.5-28.7 \mathrm{~g} / \mathrm{dL}$ and the mean cell $\mathrm{Hb}$ level is 25.9-30.6 (8-11).

Hemolytic anemia (12) is caused by extravascular destruction of red blood cells, including those with intrinsic defects, such as pyruvate kinase deficiency (13), thalassemia (14) and spherocytosis, and extrinsic defects, such as liver disease and exposure to oxidant agents. Hemolytic anemia is also caused by intravascular destruction of red blood cells due to aortic stenosis or paroxysmal nocturnal hemoglobinuria.

Hemolytic anemia (12) may result from a variety of causes, typically extravascular hemolysis due to intrinsic red blood cell (RBC) defects (e.g., pyruvate kinase deficiency (13), thalassemia (14) and spherocytosis), extrinsic factors, such as liver disease or exposure to oxidizing agents, or intravascular destruction related to aortic stenosis or paroxysmal nocturnal hemoglobinuria. We herein present two unusual cases of macrocytic anemia with an MCV in excess of $120 \mathrm{fL}$ with reticulocytosis and hemolysis that

${ }^{1}$ Department of Internal Medicine, Himeji St. Mary's Hospital, Japan and ${ }^{2}$ Department of Respiratory Internal Medicine, Himeji St. Mary's Hospital, Japan

Received for publication December 30, 2012; Accepted for publication March 13, 2013

Correspondence to Dr. Seisuke Ota, seisukeota@mail.goo.ne.jp 

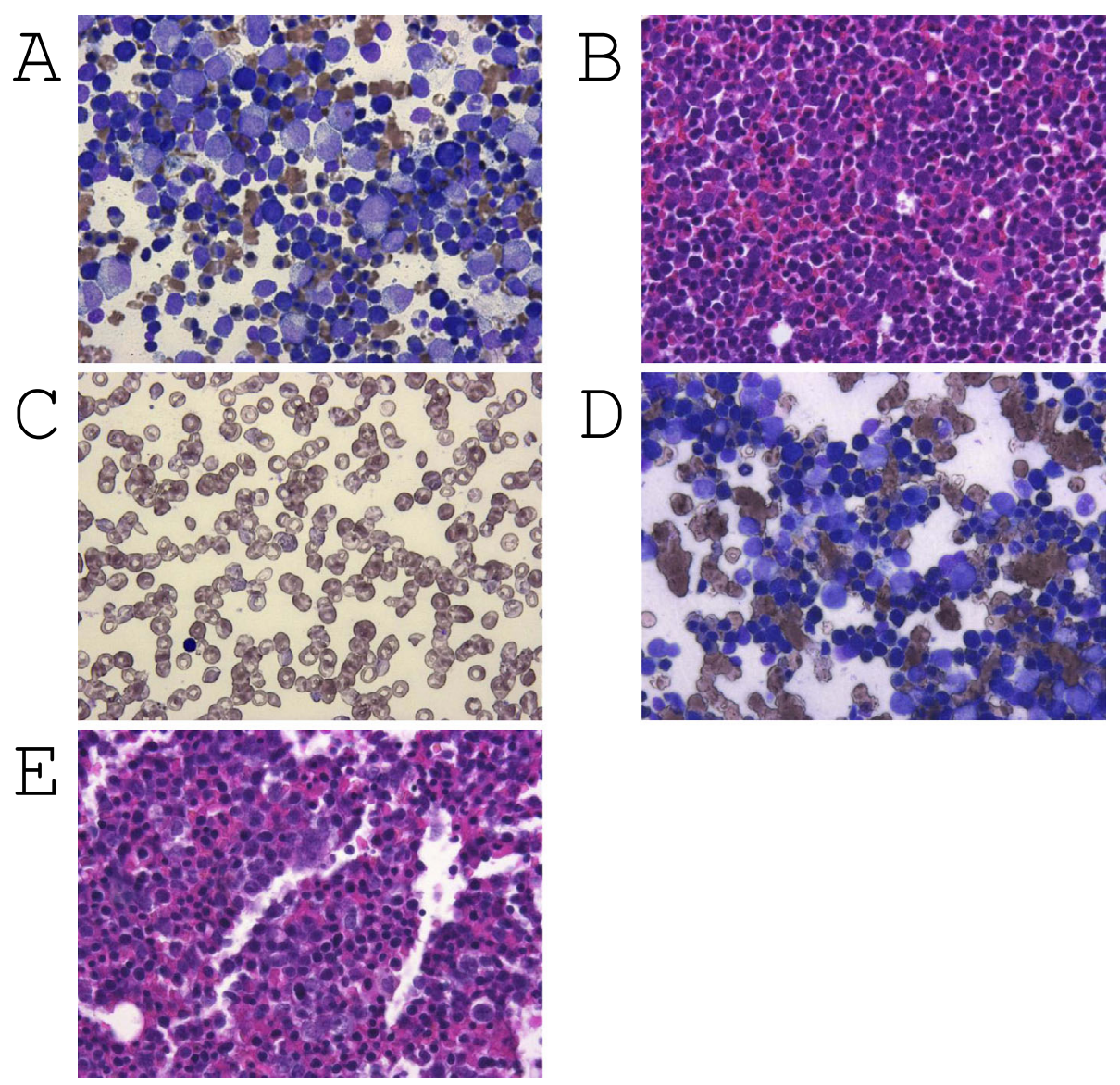

Figure. A, B. Bone marrow aspiration revealed $71.8 \%$ erythroblasts and $\mathbf{1 0 . 6 \%}$ myeloblasts in case 1 (A, May-Grünwald-Giemsa, B, Hematoxylin and Eosin (H\&E) staining, $\times 40)$. Peripheral blood showing $\mathbf{2 4 0 . 0 \%}$ o reticulocytes and a white blood cell count with a differential count of $\mathbf{4 . 0 \%}$ myeloblasts in case 2. BM aspiration revealed $68.0 \%$ erythroblasts and $5.0 \%$ myeloblasts in case 2 (D, May-Grünwald-Giemsa, E, H\&E staining, $\times 40$ ).

were diagnosed as acute erythroid leukemia (AEL).

\section{Case Reports}

\section{Case 1}

A 53-year-old woman was referred on January, 2012 with a three-month history of palpitations and dyspnea. She was severely anemic and was therefore admitted to our hospital the following day. She had no particular medical history. A blood analysis revealed macrocytic anemia with hemolysis and pancytopenia: RBC count, $9.4 \times 10^{5} / \mu \mathrm{L}$ with $60.0 \%$ reticulocytes; $\mathrm{Hb}, 3.7 \mathrm{~g} / \mathrm{dL}$; MCV, $124.5 \mathrm{fL}$; white blood cell (WBC) count, $2,800 / \mu \mathrm{L}$ with a differential count of $10.0 \%$ myeloblasts; and platelet count, $1.29 \times 10^{5} / \mu \mathrm{L}$. The elevated levels of total bilirubin $(2.1 \mathrm{mg} / \mathrm{dL})$ and lactate dehydrogenase (LDH; $486 \mathrm{IU} / \mathrm{L}$ ) were consistent with the findings of hemolysis. The level of haptoglobin was less than $10 \mathrm{mg}$ / $\mathrm{dL}$, although the type of haptoglobin was not identified. The levels of AST, ALT and $\gamma$-GTP were normal. No antiparvovirus B19 IgM antibodies were detected. Moreover, direct and indirect Coombs tests were negative, and the vitamin B12 and folic acid levels were normal. A diagnosis of
AEL was confirmed after BM aspiration revealed $71.8 \%$ erythroblasts and $10.6 \%$ myeloblasts with a nucleated count of $4.42 \times 10^{5} / \mu \mathrm{L}$ and a megakaryocyte count of $63 / \mu \mathrm{L}$ (normal range: $50-150 / \mu \mathrm{L}$ ) (Figure A, B). As the percentage of erythroblasts was $71.8 \%$, the percentage of non-erythroid cells was $28.2 \%$. Therefore, the proportion of $10.6 \%$ of the myeloblasts in $28.2 \%$ of the non-erythroid cells was $37.5 \%$ (Table 1). The erythroblasts exhibited megaloblastic-like abnormalities with lobulated nuclei. The neutrophils demonstrated degradation, and the number of mature neutrophils was decreased. The number of megakaryocytes was increased, and micromegakaryocytes were observed. A cytogenetic analysis revealed a normal karyotype $(46, \mathrm{XY})$ in 20 cells. Thereafter, the patient was referred to another hospital for high-dose chemotherapy with BM transplantation on day 11 of admission.

\section{Case 2}

A 42-year-old man was referred to our hospital on September, 2012 with a week-long history of dizziness. He had no particular medical history. A blood analysis revealed macrocytic anemia: RBC count, $1.63 \times 10^{6} / \mu \mathrm{L}$ with $240.0 \%$ o reticulocytes; Hb, 6.0 g/dL; MCV, $120.2 \mathrm{fL}$; WBC count, 
Table 1. Marrow Differential Cell Count in Case 1

\begin{tabular}{llrr}
\hline Group & Cell type & Fraction & $\begin{array}{r}\text { Reference } \\
\text { range (\%) }\end{array}$ \\
\hline & Myeloblasts & $10.6 \%$ & $0.2-2.9$ \\
& Promyelocytes & $8.8 \%$ & $1.5-8.4$ \\
& Myelocytes & $2.6 \%$ & $1.0-9.7$ \\
& Metamyelocytes & $2.6 \%$ & $3.6-14.6$ \\
Cells of myelopoiesis & Band cells & $0.8 \%$ & $10.6-24.6$ \\
& Segmented neutrophils & $1.2 \%$ & $8.5-33.2$ \\
\cline { 2 - 4 } & Eosinophils & $0.8 \%$ & $1.2-5.3$ \\
& Basophils & $0.2 \%$ & $0-0.8$ \\
\cline { 2 - 4 } Cells of erythropoiesis & Total & $25.4 \%$ & $50.4-70.5$ \\
\hline & Proerythroblasts & $1.4 \%$ & $0.2-1.3$ \\
& Basophilic erythroblasts & $3.1 \%$ & $0.8-6.7$ \\
& Polychromatic erythroblasts & $62.1 \%$ & $4.1-29.1$ \\
& Orthochromatic erythroblast & $5.2 \%$ & $0.1-5.7$ \\
\cline { 2 - 4 } & Total & 71.8 & $18.4-33.8$ \\
\hline \multirow{3}{*}{ Other cell types } & Megakaryocytes & $0.2 \%$ & $0-0.1$ \\
& Plasma cells & $0.2 \%$ & $0.2-1.7$ \\
& Reticular cells & $0.2 \%$ & $0-3.9$ \\
& Lymphocytes & $2.2 \%$ & $5.0-32.6$ \\
& Monocytes & $0 \%$ & $0.7-6.0$ \\
\hline
\end{tabular}

$3,100 / \mu \mathrm{L}$ with a differential count of $4.0 \%$ myeloblasts; and platelet count, $3.0 \times 10^{4} / \mu \mathrm{L}$ (Figure C). The elevated levels of total bilirubin $(2.3 \mathrm{mg} / \mathrm{dL})$ and $\mathrm{LDH}(458 \mathrm{IU} / \mathrm{L})$ were consistent with a diagnosis of hemolysis. The levels of AST, ALT and $\gamma$-GTP were normal, as were the levels of vitamin B12 and folic acid levels. The level of haptoglobin was not measured. Furthermore, BM aspiration revealed $68.0 \%$ erythroblasts, $5.0 \%$ myeloblasts with $3.03 \times 10^{5} / \mu \mathrm{L}$ nucleated cells and $50 / \mu \mathrm{L}$ megakaryocytes (normal range: $50-150 / \mu \mathrm{L}$ ) (Figure D, E). As the percentage of erythroblasts was $68.0 \%$, the percentage of non-erythroid cells was $32.0 \%$. Therefore, the proportion of $5.0 \%$ of the myeloblasts in $32.0 \%$ of the non-erythroid cells was $15.6 \%$. The erythroblasts exhibited megaloblastic-like abnormalities with lobulated nuclei. The neutrophils demonstrated degradation, and the number of mature neutrophils was decreased. The number of megakaryocytes was not increased; however, micromegakaryocytes were observed (Table 2). The proportion of myeloblasts was greater than $20 \%$ of non-erythroid cells in the BM biopsy specimen. Immunostaining of the BM biopsy specimen was negative for CD34, positive for glycophorin $\mathrm{C}$ and partially positive for fetal $\mathrm{Hb}(\mathrm{HbF})$. The patient was diagnosed with AEL. A cytogenetic analysis of 20 cells demonstrated $48, \mathrm{XY},+8,+21$ in all cells. Subsequently, the patient was referred to another hospital for high-dose chemotherapy with BM transplantation.

\section{Discussion}

AEL (M6) is a rare type of leukemia, accounting for less than $5 \%$ of all acute myeloid leukemia (AML) cases. In the 1985 revision of the French-American-British (FAB) classification (15), the AML-M6 diagnostic criteria were refined to include the following: erythroblasts represent $\geq 50 \%$ of all nucleated BM cells; prominent dyserythropoiesis; and myeloblasts represent $\geq 30 \%$ of non-erythroid BM cells. Consequently, the two types of AEL recognized include the
Table 2. Marrow Differential Cell Count in Case 2

\begin{tabular}{llrr}
\hline Group & Cell type & Fraction & $\begin{array}{r}\text { Reference } \\
\text { range (\%) }\end{array}$ \\
\hline & Myeloblasts & $5.0 \%$ & $0.2-2.9$ \\
& Promyelocytes & $4.4 \%$ & $1.5-8.4$ \\
& Myelocytes & $3.2 \%$ & $1.0-9.7$ \\
Cells of myelopoiesis & Metamyelocytes & $3.8 \%$ & $3.6-14.6$ \\
& Band cells & $4.0 \%$ & $10.6-24.6$ \\
& Segmented neutrophils & $2.4 \%$ & $8.5-33.2$ \\
\cline { 2 - 4 } & Eosinophils & $0.2 \%$ & $1.2-5.3$ \\
& Basophils & $0.8 \%$ & $0-0.8$ \\
\cline { 2 - 4 } Cells of erythropoiesis & Total & $23.8 \%$ & $50.4-70.5$ \\
\hline & Proerythroblasts & $1.4 \%$ & $0.2-1.3$ \\
& Polychrophilic erythroblasts & $2.2 \%$ & $0.8-6.7$ \\
& Orthochromatic erythroblast & $61.8 \%$ & $4.1-29.1$ \\
\cline { 2 - 4 } & Total & $2.6 \%$ & $0.1-5.7$ \\
\hline \multirow{3}{*}{ Other cell types } & Megakaryocytes & $68.0 \%$ & $18.4-33.8$ \\
\hline & Plasma cells & $0 \%$ & $0-0.1$ \\
& Reticular cells & $0.2 \%$ & $0.2-1.7$ \\
& Lymphocytes & $0.2 \%$ & $0-3.9$ \\
& Monocytes & $5.8 \%$ & $5.0-32.6$ \\
\hline
\end{tabular}

erythroid/myeloid type and the "pure" type. In erythroid/ myeloid AEL, erythroid precursors represent $>50 \%$ of all nucleated BM cells and myeloblasts account for $>20 \%$ of all non-erythroid cells (16-21). Both cases 1 and 2 were of the erythroid/myeloid AEL type.

The clinical features are often relatively nonspecific and include pallor, fever and hepatosplenomegaly. Extramedullary presentations, such as myeloid sarcoma, are unusual in patients with AEL; however, extramedullary sites can be involved, and the diagnosis of AEL is usually established based on the findings of lymph node biopsies. Anemia is often severe in patients with AEL, with a mean hemoglobin level of $7.5 \mathrm{~g} / \mathrm{dL}$ reported (22). Domingo-Claros A et al. reviewed a series of 62 patients with erythroid neoplastic proliferation. Fifty-three patients met the criteria for the M6a subtype of the WHO classification, and two patients were classified as having pure erythremia (M6b). Seven of the cases could not be classified according to the WHO criteria in 2001. The median MCV was $96 \mathrm{fL}$ (range: 71-118) (23). As the MCV in both of the present cases was greater than $120 \mathrm{fL}$, the patients exhibited markedly high MCVs, even for patients with AEL. Thrombocytopenia and leukopenia, to varying degrees, are also common. Up to one-third of patients can develop hemorrhage, hepatomegaly or splenomegaly. In general, AEL exhibits an aggressive clinical course. Less favorable outcomes are observed in the elderly, patients with a previous diagnosis of MDS and those who have undergone chemotherapy for previous neoplasms (22). Therefore, high-dose chemotherapy followed by BM transplantation or peripheral blood stem cell transplantation is recommended for all patients with AEL (24).

Both of the current patients presented with macrocytic anemia, with peripheral reticulocytosis contributing to at least some extent (6\% of peripheral RBCs in case 1 and $24 \%$ of peripheral RBCs in case 2). Because a normal reticulocyte MCV is only 103-126 fL (8-11), reticulocytosis was unlikely to be the only factor contributing to macrocy- 
tosis in these cases, as the MCV was $>120 \mathrm{fL}$ in both patients, and the reticulocyte counts were considerably $<100 \%$. Therefore, some other factors, such as MDS, may have also accounted for the macrocytic anemia observed in these patients. The karyotype of $48, \mathrm{XY},+8,+21$ demonstrated in case 2 is sometimes seen in patients with MDS. However, even if the coexistence of MDS was present, MDS alone could not have caused macrocytic anemia with an MCV $>120$ fL. Therefore, marked reticulocytosis and underlying MDS or erythropoiesis abnormalities due to AEL additively could have caused the marked macrocytic anemia. Neither of the patients were alcohol abusers, and there were no findings suggestive of liver disease.

The present patients exhibited the characteristics of hemolytic anemia, including elevated total bilirubin and LDH levels and decreased haptoglobin levels. Hemolysis can occur in patients with AEL and may be severe (25). Although we do not know whether the hemolysis observed in these cases was responsible for the severe macrocytosis, it is likely that the abnormal RBCs produced by AEL-affected BM are more easily destroyed, thereby accounting for the hemolysis.

The number of reported cases of AEL is quite small compared with the more typical causes of macrocytic anemia, such as folate or cobalamin deficiency, liver disease, including alcoholism, and adverse drug effects, as well as other causes of hemolysis. However, the details of the present cases suggest that AEL should be considered in the differential diagnosis of macrocytic anemia, especially when hemolysis and/or peripheral reticulocytosis are present.

The authors state that they have no Conflict of Interest (COI).

\section{Acknowledgement}

We thank Ms. Megumi Matsumoto and Ms. Nobuko Fujio for their valuable technical assistance and Dr. Eijiro Omoto for his useful advice and suggestions.

\section{References}

1. Snower DP, Weil SC. Changing etiology of macrocytosis. Zidovudine as a frequent causative factor. Am J Clin Pathol 99: 57-60, 1993.

2. Pruthi RK, Tefferi A. Pernicious anemia revisited. Mayo Clin Proc 69: 144-150, 1994.

3. Savage DG, Lindenbaum J, Stabler SP, Allen RH. Sensitivity of serum methylmalonic acid and total homocysteine determinations for diagnosing cobalamin and folate deficiencies. Am J Med 96: 239-246, 1994.

4. Seppä K, Sillanaukee P, Saarni M. Blood count and hematologic morphology in nonanemic macrocytosis: differences between alcohol abuse and pernicious anemia. Alcohol 10: 343-347, 1993.

5. Slovak ML, Kopecky KJ, Cassileth PA, et al. Karyotypic analysis predicts outcome of preremission and postremission therapy in adult acute myeloid leukemia: a Southwest Oncology Group/East- ern Cooperative Oncology Group Study. Blood 96: 4075-4083, 2000.

6. Letendre L, Noel P, Litzow MR, Hoagland HC, Tefferi A. Treatment of acute myelogenous leukemia in the older patient with attenuated high-dose ara-C. Am J Clin Oncol 21: 142-144, 1998.

7. Wahlin A, Markevärn B, Golovleva I, Nilsson M. Prognostic significance of risk group stratification in elderly patients with acute myeloid leukaemia. Br J Haematol 115: 25-33, 2001.

8. Hoffbrand V, Provan D. ABC of clinical haematology. Macrocytic anaemias. BMJ 314: 430-433, 1997.

9. Colon-Otero G, Menke D, Hook CC. A practical approach to the differential diagnosis and evaluation of the adult patient with macrocytic anemia. Med Clin North Am 76: 581-597, 1992.

10. d'Onofrio G, Chirillo R, Zini G, Caenaro G, Tommasi M, Micciulli G. Simultaneous measurement of reticulocyte and red blood cell indices in healthy subjects and patients with microcytic and macrocytic anemia. Blood 85: 818-823, 1995.

11. Houwen B. Reticulocyte maturation. Blood Cells 18: 167, 1992.

12. Guillaud C, Loustau V, Michel M. Hemolytic anemia in adults: main causes and diagnostic procedures. Expert Rev Hematol 5: 229-241, 2012.

13. Jacobasch G, Rapoport SM. Hemolytic anemias due to erythrocyte enzyme deficiencies. Mol Aspects Med 17: 143-170, 1996.

14. Harano K, Harano T. Case of deletion type beta(0)-thalassemia found in an Asian (Malaysian) family living in Japan. Rinsho Byori 58: 325-331, 2010 (in Japanese, Abstract in English).

15. Bennett JM, Catovsky D, Daniel MT, et al. Proposed revised criteria for the classification of acute myeloid leukemia: a report of the French-American-British Cooperative Group. Ann Intern Med 103: 620-625, 1985.

16. Yamamoto JF, Goodman MT. Patterns of leukemia incidence in the United States by subtype and demographic characteristics, 1997-2002. Cancer Causes Control 19: 379-390, 2008.

17. Sant M, Allemani C, Tereanu $C$, et al. Incidence of hematologic malignancies in Europe by morphologic subtype: results of the HAEMACARE project. Blood 116: 3724-3734, 2010.

18. Smith A, Howell D, Patmore R, Jack A, Roman E. Incidence of haematological malignancy by sub-type: a report from the Haematological Malignancy Research Network. Br J Cancer 105: 16841692, 2011.

19. Dores GM, Devesa SS, Curtis RE, Linet MS, Morton LM. Acute leukemia incidence and patient survival among children and adults in the United States, 2001-2007. Blood 119: 34-43, 2012.

20. Meyers CA, Albitar M, Estey E. Cognitive impairment, fatigue, and cytokine levels in patients with acute myelogenous leukemia or myelodysplastic syndrome. Cancer 104: 788-793, 2005.

21. Swerdlow SH, Campo E, Harris NL, et al. World Health Organization Classification of Tumours of Haematopoietic and Lymphoid Tissues. IARC Press, Lyon, 2008.

22. Zuo Z, Polski JM, Kasyan A, Medeiros LJ. Acute erythroid leukemia. Arch Pathol Lab Med 134: 1261-1270, 2010.

23. Domingo-Claros A, Larriba I, Rozman M, et al. Acute erythroid neoplastic proliferations. A biological study based on 62 patients. Haematologica 87: 148-153, 2002.

24. Killick S, Matutes E, Powles RL, et al. Acute erythroid leukemia (M6): outcome of bone marrow transplantation. Leuk Lymphoma 35: 99-107, 1999.

25. Zebisch A, Sill H. Severe hemolysis as presenting sign of acute erythroleukemia. J Clin Oncol 26: 330-331, 2008.

(C) 2013 The Japanese Society of Internal Medicine http://www.naika.or.jp/imonline/index.html 